Original Article (short paper)

\title{
Strategies for coaches' development in a football club: a learning organization
}

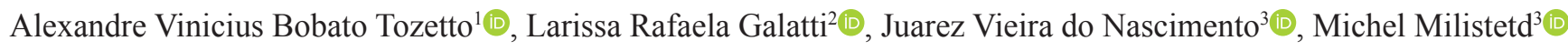 \\ ${ }^{1}$ Universidade do Estado de Santa Catarina, UDESC, Florianópolis, SC, Brazil; ${ }^{2}$ Universidade Estadual de Campinas, \\ UNICAMP, Limeira, SP, Brazil; ${ }^{3}$ Universidade Federal de Santa Catarina, UFSC, Florianópolis, SC, Brazil
}

\begin{abstract}
Aim: The aim of this study was to identify the strategies adopted in a football club to support coaches' development. Methods: Eight coaches and four technical coordinators from a Brazilian elite club participated. After transcribing data from semi-structured interviews with coaches and technical coordinators, they were analyzed using the QSR Nvivo 9.2 software. Results: Three support schemes and their respective pillars of action were identified: a) Mentoring and meeting - Assistance among coaches, discussions with coaching staff, and free theme meetings; b) Incentive for continuing education; c) Club Pillars - Club goals, continuity of coaches, evaluation of coaches. Conclusion: Data allowed us to identify the important contributions of this Club in continued ongoing coach development. Moreover, we may characterize the Club as an authentic learning organization due to the promotion of a safe work environment that stimulates coaches' engagement in the Club's organizational culture and enables adequate communication and the constant update through courses and meetings.
\end{abstract}

Keywords: organizational learning, sports coaches, soccer, elite club, team sports.

\section{Introduction}

In the sport performance context, the search for better results demands excellence in athletes' preparation and, consequently, highly qualified coaches to conduct the training and competition processes ${ }^{1}$. The competitive sports environment requires high dedication from coaches, who need to be constantly learning, reassessing practices, making decisions, and reflecting in order to maintain and achieve their results and goals ${ }^{2}$. However, the formal coach education programs, with pre-defined content to be followed in classes do not seem to meet all particular demands that each coach has in this competitive context ${ }^{3,4}$. Cassidy, Jones, and Potrac ${ }^{5}$ and Mesquita, Ribeiro, Santos, Morgan $^{6}$, suggest that a negative aspect of the formal courses of instruction would be the distance between theory and practice in which coaches find difficulties in transferring the content taught in class to their daily environments.

Thus, for coaches to keep developing and learning, work environments have been recognized as contexts for continuous learning ${ }^{7-10}$ because of coaches' need to change constantly in order to be updated according to the situations of their social context and become relevant to their members ${ }^{11,12}$. The workplace as a learning organization becomes a convenient way of supporting continuous learning. In this organizational structure, strategies can be established to foster organizational improvements ${ }^{12}$. According to Hunter-Johnson and Closson ${ }^{12}$ such strategies can include promoting a safe culture to share experiences (positive and negative) as a learning opportunity and encourage the implementation of a reward and recognition system that supports learning practices for both individuals and teams.
Specifically, in coach development, the practical involvement in daily tasks, observing and exchanging information in sport organizations, comprises the main knowledge sources for highperformance coaches ${ }^{13,14}$ and youth coaches ${ }^{3,10,15}$. However, even though the learning organization exhibits continuous guidelines that support professionals to learn intensively, it does not mean that learning will be effective. Some professionals may learn in different ways and levels (e.g. individual, and team or organizations with different people), and some may simply not learn the organization's practices and culture ${ }^{11,12,16}$. This can happen because they show distinct biographies (i.e. the manner we have been molded by previous learning experiences $)^{11}$, and may not learn without specific initiatives (e.g. instruction and initial guidance for new employees - peer instructions, training with instructors about work activities; meetings, seminars, internal courses, and so on - formalized interaction; learning through conversations and interviews - informal or casual; among others) oriented towards learning ${ }^{16}$.

Therefore, the learning processes in the organization must consider the differences among functions, experiences, and knowledge of its participants. In addition, Cushion, Ford, and Williams ${ }^{17}$, describe that it is necessary to promote the awareness of the practitioners involved in sports, including the need for practice to be evidence-based in an attempt to identify principles for best practices and ways of training and development of young athletes. According to Milistetd, Peniza, Trudel, Paquette ${ }^{18}$, there is always room for improvement, where learning structured through a 'Personal Learning Coach' (PLC) can be one of the strategies to facilitate coach development.

Despite recent findings, the literature on the learning of high-performance sports coaches in the professional workplace 
has been largely overlooked ${ }^{8}$. The literature ${ }^{19,20}$ on lifelong learning by youth coaches indicates the impact of the workplace on their development. However, the organization's coaching practices were not the focus of these studies and were therefore not detailed. In this sense, Culver and Trude ${ }^{21}$ suggestion is to provide practice experiences in the workplace, with Communities of Practice possible pathways for learning and "for transforming sport cultures into entities primarily concerned with developing athletes (whether it is for high performance or lifelong participation)" (p. 8).

The search for more information about professionals' learning in the work environment is crucial in order to contribute to a deep understanding of the complexity and dynamics of the workplace as an integrated whole ${ }^{7,16}$. This is especially the case in sport, given the negotiations that occur between coaches and the sport "culture" where mistakes are recognized and corrected quickly and conveniently, can favor greater learning and performance of coaches and athletes ${ }^{2,7}$. Thus, sports associations, clubs, and their respective leaders need information about how to foster the learning of coaches and other professionals who support athlete training at the level of youth performance ${ }^{20}$ and high performance ${ }^{8}$.

Given the possibility of viewing the Sports Club as a learning organization that favors the continuous professional development of its coaches, the aim of this study was to identify the strategies for coach development within the workplace as described by the technical coordinators and the coaches in a Professional Football Club in Brazil.

\section{Methods}

\section{The case}

This study is characterized as an intrinsic case study ${ }^{22}$. The exploratory intrinsic case study has as its basis a real interest on a single situation aiming to understand a case ${ }^{22}$. The case study enables the researcher to answer the "how" question, by considering how a phenomenon is influenced by the situation. For this, different data sources are used to merge the information and have a broader view of the case studied ${ }^{23}$. Considering the lack of official club documents in this case that deal with coach development, data triangulation was achieved through the collection of data from both coaches and technical coordinators.

The coaches and technical coordinators were deliberately chosen from a Professional Football Club in Brazil that has formative, athlete detection, and selection processes instituted for elite football. Indeed, the club was chosen because it was one of the first in the national youth sport ranking during the period of this research ${ }^{24}$. The club has more than 200 athletes in nine age group teams (U10; U11; U12; U13; U14; U15; U16; U17; U21) in addition to the professional team and athletes in a test period with the Club. Each age group team has a coach, a physical trainer, and a goalkeeper coach. From U16 to U21, assistant coaches are also included. During competitions, a group of performance analysts is responsible for recording and verifying the teams' development, later passing on the videos to the coaching staff.
The coaches also have the support of professionals from other areas, such as psychologists, nutritionists, social assistants, physiotherapists, and doctors, among others.

\section{Participants}

The participants were coaches and technical coordinators responsible for the training of the Club's young athletes.

\section{Sports Coaches}

Eight youth coaches participated in the study $(\mathrm{C} 1, \mathrm{C} 2, \mathrm{C} 3$, $\mathrm{C} 4, \mathrm{C} 5, \mathrm{C} 6, \mathrm{C} 7$, and C8), aged about $31 \pm 3,58$ years. All coaches were male and held a bachelor's degree in Physical Education. In addition, six of these coaches $(\mathrm{C} 1, \mathrm{C} 2, \mathrm{C} 4, \mathrm{C} 6, \mathrm{C} 7$, and C8) obtained degrees with sport-specific specialization (table 1). These specialization courses are offered as a continued education opportunity (e.g. sports biomechanics applied to training, physical conditioning in sports), and must have a minimum duration of 360 hours $^{25}$. Additional information is presented in table 1.

Table 1. Characterization of youth coaches.

\begin{tabular}{cclcc}
\hline Coach & Age & \multicolumn{1}{c}{ Formation (year) } & Coach* & Groups \\
\hline C1 & 29 & Specialization (2009) & 10 & U11 \\
C2 & 28 & Specialization (2010) & 6 & U12 \\
C3 & 33 & Graduated (2010) & 10 & U13 \\
C4 & 31 & Specialization (2012) & 4 & U10 \\
C5 & 32 & Graduated (2009) & 11 & U17 \\
C6 & 39 & Specialization (2006) & 14 & U16 \\
C7 & 28 & Specialization (2011) & 7 & U15 \\
C8 & 31 & Specialization (2009) & 10 & U14 \\
\hline
\end{tabular}

* Years of sports coaching.

\section{Technical Coordinators}

The coordinators were responsible for a series of tasks within the club, such as: registering athletes, scheduling team trips, and developing coaches, besides their actual administrative and political work. Notably, they facilitate interaction among coaches, coaching staff members, athletes, directors, and professionals from other areas, as well as having a role communicating with athletes' parents and other people outside the Club. They lead a group of coaches and help in the planning, guidance, coordination, and execution of many activities. An example is their involvement in the evaluation of athletes and coaching staff, always aiming at maximizing the teams' results.

The four technical coordinators (TC1, TC2, TC3, and TC4), all males, were on average $37 \pm 2,87$ years old. They all held Physical Education degrees and had been working in the Club from seven months to 11 years. Each technical coordinator was responsible for two teams, as follows: TC1 - U10-U11; TC2 - U12-U13; TC3 - U14-U15; TC4 - U16-U17. 


\section{Data collection instruments}

Semi-structured interviews were performed with the coaches and technical coordinators. For Purdy ${ }^{26}$ and Sparkes and Smith ${ }^{27}$, more than one type of interview can be used for data collection. The combination of different types of the interview can address and further detail the data of the research context with a thorough and revealing clarification about the meanings that the research participants give to their experiences.

A pilot study was carried out by the first author with three youth football coaches to familiarize the interviewer with the research process. After the pilot study in a similar context, the research questions were improved to better reflect the defined themes in order to collect in-depth data, in a process (script design and data analysis) conducted by two Ph.D. with over 10 years of experience in qualitative research, and one Master student.

\section{Data collection procedures}

The study was approved by the Committee for Ethics on Human Beings Research from the Federal University of Santa Catarina (Statement no. 1,285,811/2015) as all ethical precautions were taken, and participants signed written informed consent.

Semi-structured interviews were carried out after the prior contact by e-mail and in person with the coaches and technical coordinators. After participants agreed to participate in the study, interviews were conducted at a location of choice at a time that was most convenient for them. The interviews were preferably held in a private place, where only participants and the first author were present to prevent distractions.

The researcher digitally recorded the interviews that were guided by themes about the club, first conducted with the coaches and reinforced with interviews with the technical coordinators. Questions to coaches included: Can you describe the structure and organization of your sports club? What roles do you play in the club or have you taken over? Is there a person with whom you live and who influences your training (or coaching)? Has your way of training (your philosophy) changed over time? Please describe. What do you think of the weekly meetings to discuss football-related topics? What do you think about the club providing financial resources for coaches to take courses?

Questions to the coordinators reinforced the data: "Is there a working idea for the club that is being developed with the coaches? How does the club implement this work idea with the coaches? How does the club plan investments to help youth coaches? And coach training?"

Finally, some questions were directed to both coaches and coordinators, for a greater detail of the data. "Does the club offer training courses? How often are meetings held with the coaches? How are these meetings organized and what are the contents discussed?" In this regard, the author followed the recommendations of Sparkes and Smith ${ }^{27}$, leaving the interviewees with total freedom to elaborate the answers.

The interviews with the coaches lasted an average of 58 minutes, those with the technical coordinators lasted an average of 47 minutes. The interviews were transcribed and were imported into QSR Nvivo 9.2 software.

\section{Data analysis}

The analysis of the data occurred in an inductive way. According to Thomas ${ }^{28}$, the inductive analysis provides a simple and direct approach, for possible discoveries in the research context. The author ${ }^{28}$ describes the inductive analysis as the detailed reading of raw data to derive concepts, or a model through interpretations by a researcher.

The data analysis procedures by Bardin ${ }^{29}$ were applied in three moments: pre-analysis, material exploration, and results'treatment and interpretation. Pre-analysis comprised the information organization, in which the interviews were transcribed, and, after an exhaustive reading, the illustrative themes sorted out. In the material exploration, the aim was to understand the meaning given by the participants to the focus of the study (learning organization). In this phase, the themes repeated throughout the quotes of the coaches were codified, which allowed us to understand the club as a possible learning organization. The last step, treatment and interpretation of results, depicts the synthesis and selection of significant data according to the interpretation of coaches and technical coordinators' interviews, including the categories of analysis - support schemes; pillars of action.

Data were collected and analyzed in Brazilian Portuguese. The translation of the study findings into the English language was carried out by professionals of a writing center with more than 10 years of experience. In the transcriptions of the interviews, the oral quotes and grammaticality were respected, in order to preserve the semantic content of the surveyed answers ${ }^{30}$.

Some strategies were used to guarantee data trustworthiness, such as triangulation of data through different types of informants and discussion sessions between authors ${ }^{31}$.

The confirmation of category representation ${ }^{32}$ was established by exhaustive analysis and discussion of two authors in this paper who are highly experienced in qualitative research, professional education, and sport. The transcripts and interpretations of data ${ }^{33}$ consisted of member checking, by sending selected parts of the transcriptions and the authors' explanations to the participants via e-mail to ask for their comments and confirmation. The process of reviewing the quotes by the participants themselves did not result in changes in the transcripts.

\section{Results and discussion}

Data from coaches and technical coordinators' interviews resulted in three support schemes and six pillars of action (Chart 1). By organizing and offering support and actions towards the coaches' development, the surveyed Club can be considered a context that encourages the football coaches' learning. 
Chart 1. Support schemes, actions, and description of pillars of action presented by coaches and technical coordinators of an Elite Football Club.

\begin{tabular}{|c|c|c|c|}
\hline Support schemes & Pillars of Action & $\begin{array}{l}\text { Coaches and Technical } \\
\text { Coordinators }\end{array}$ & Description of actions \\
\hline \multirow{3}{*}{$\begin{array}{l}\text { Mentoring and } \\
\text { meeting }\end{array}$} & $\begin{array}{l}\text { Assistance between the } \\
\text { coaches }\end{array}$ & $\begin{array}{l}\mathrm{C} 4, \mathrm{C} 7, \mathrm{C} 8, \mathrm{TC} 1, \mathrm{TC} 2 \\
\mathrm{TC} 3, \mathrm{TC} 4\end{array}$ & $\begin{array}{l}\text { Cooperation among coaches from diverse categories, as in the } \\
\text { training structuring. }\end{array}$ \\
\hline & $\begin{array}{l}\text { Discussions with the } \\
\text { coaching staff }\end{array}$ & $\mathrm{C} 1, \mathrm{C} 3, \mathrm{C} 5, \mathrm{TC} 2, \mathrm{TC} 4$ & $\begin{array}{l}\text { Coaches always discuss with their coaching staff about planning. } \\
\text { Before training, they talk about what is going to be explored and } \\
\text { after about what happened in the trainings. }\end{array}$ \\
\hline & Free theme meetings & $\begin{array}{l}\mathrm{C} 5, \mathrm{C} 7, \mathrm{C} 8, \mathrm{TC} 1, \mathrm{TC} 2 \\
\mathrm{TC} 3, \mathrm{TC} 4\end{array}$ & $\begin{array}{l}\text { Meetings schedule defined at the beginning of each year. Each } \\
\text { meeting is under the responsibility of one professional, who } \\
\text { chooses a theme and presents it to the colleagues. After the } \\
\text { presentation, the professionals discuss about what was presented. }\end{array}$ \\
\hline $\begin{array}{l}\text { Incentive for } \\
\text { continuing } \\
\text { education }\end{array}$ & & $\begin{array}{l}\mathrm{C} 1, \mathrm{C} 2, \mathrm{C} 3, \mathrm{C} 8, \mathrm{TC} 1 \\
\mathrm{TC} 2, \mathrm{TC} 3, \mathrm{TC} 4\end{array}$ & $\begin{array}{l}\text { Club sponsoring, entirely or partially, the expenses of courses } \\
\text { taken by coaches. }\end{array}$ \\
\hline \multirow{3}{*}{ Club Pillars } & Club goals & $\mathrm{C} 2, \mathrm{C} 8, \mathrm{TC} 1, \mathrm{TC} 2, \mathrm{TC} 3$ & $\begin{array}{l}\text { Coaches and coordinators report on the clarity of the club goals, } \\
\text { with a concern about the holistic learning of their athletes. }\end{array}$ \\
\hline & Continuity of coaches & $\begin{array}{l}\mathrm{C} 6, \mathrm{C} 8, \mathrm{TC} 1, \mathrm{TC} 2, \mathrm{TC} 3 \\
\mathrm{TC} 4\end{array}$ & $\begin{array}{l}\text { Safety, as in job perceived by coaches and coordinators when } \\
\text { staying in the Club, even when the teams' competitive goals are } \\
\text { not achieved. Thus, coaches have the time to learn the philosophy } \\
\text { of the club. }\end{array}$ \\
\hline & Evaluation of coaches & $\begin{array}{l}\mathrm{C} 1, \mathrm{C} 4, \mathrm{C} 5, \mathrm{C} 8, \mathrm{TC} 1 \\
\mathrm{TC} 2, \mathrm{TC} 3, \mathrm{TC} 4\end{array}$ & $\begin{array}{l}\text { Evaluation of methodological procedures and behaviors adopted } \\
\text { by coaches. Thus, managers can monitor the development of } \\
\text { coaches. }\end{array}$ \\
\hline
\end{tabular}

\section{Mentoring and meetings}

The theme 'mentoring and meetings' can be understood as the situations in which the coaches meet and discuss the process of sports training. In this theme, participants indicated that mentors and meetings with other coaches helped them in their training methods (C8), to determine if they have achieved their goals (C5), and to acquire knowledge (C7).

\section{Assistance between the coaches}

The first action identified among the "mentoring and meetings" concerns the "assistance between the coaches" ( $\mathrm{C} 4$, $\mathrm{C} 7, \mathrm{C} 8, \mathrm{TC} 1, \mathrm{TC} 2, \mathrm{TC} 3$, and TC4).

"[...] the best school I had I think it was here [...] I stayed four years in the youth 'football school', you stay there as assistant of coaches and with those guys I had lots of experience to be able to maybe create my way of training and planning my training [...]" (C8).

"[...] at first you had the internship guys there, always following a graduated coach and after some learning time, when the directors think you're apt, there is no set time, [...] you stop following [...] another coach and starts to be the head coach of a team" (TC4).

The assistance between the coaches included episodes that can lead them to develop their own working philosophy, especially during observation and discussions with more experienced head coaches who become mentors (C8 and TC4).

\section{Discussions with the coaching staff}

Another pillar of action comprised the "discussions with the coaching staff" about the training process (plan, act, and evaluate) of the athletes and about the performance of the team in the competition.

"[...] We do video analysis (of the competition), discussion about the week's training and we always try to sit down, share tasks that will happen during and after training. We always talk about how our training was if we didn't achieve the goals [...]" (C5).

"[...] They (coaches) arrive in the Club and already start to do their practice planning. Anyway, the training is already defined in the week program, but it needs to be well developed [...]. The Club is building, for next year, a kind of library (with books on themes related to the sport), so that the coaches can have a space [...] where they can work, [...] to encourage everyone (to plan training in advance in an appropriate location) [...]" (TC2).

This action happens not only as a formality and as a demand from the Club, but also to further encourage the informal discussions and studies in a space dedicated to the Club's 
own library (TC2), which C5 identified that can facilitate the achievement of goals and objectives.

\section{Free theme meetings}

To complement the coach development strategies, and to encourage the coaches' learning, free theme meetings as explained by (C5, C7, C8, TC1, TC2, TC3, and TC4) happen through meetings inside the training center.

The "Free theme meetings" are realized systematically and weekly, in which each professional, including all coaches, is responsible for conducting a Football-related lecture during the season.

\section{"[...] there is a group that, once a week we present themes, each professional involved in the field has to develop a subject and that makes us look for knowledge, having to present these contents for other people [...]" (C7). \\ "[...] we get together once a week and one of our professionals gives a speech on some subject. It is almost two hours of the meeting, because everybody starts to debate. The presentation lasts fifteen minutes, but the guys go on discussing. No one is obligated to go, but the auditorium is almost always full [...]" (TC4).}

The meetings in the Club, besides enabling learning, reduce time and money spent on trips, accommodations, and subscriptions for courses outside the Club.

The results of this study on "mentoring and meetings" are similar to the Jones, Armour, and Potrac ${ }^{34}$ findings of a football coach in England, who, in socializing in the Club, changed his way of coaching and changed his philosophy, especially because of his experiences with a more experienced coach.

In this club in Europe, the season training program, outlining aspects of how the teams would play and train throughout the year, reinforced for the coach that all coaches were aware of in united to support the goals that were presented to them and because of that, all teams and players shared the same goals and responsibilities ${ }^{34}$.

In the context investigated in this study, in the period of adaptation to the club, the newcomers (i.e. coaches new to the environment) learn from the more experienced coaches (C8 and TC4). An aspect highlighted by Jarvis ${ }^{11}$ is that a large share of what is learned is not controlled or planned and learning occurs incidentally. In this case, organizational leaders, in recognizing the importance of opportunities for reflection and sharing of information, need to consider that greater effectiveness depends on people within organizations being open to receiving and sharing their experiences with others, rather than competition among professionals, as in the case of more experienced professionals teaching their job to younger professionals.

A number of studies ${ }^{6-8,13,14,21,35,36}$ consider as a necessity for professional development, the learning process shared among all professionals involved in the organization and not just the sharing of information between a more experienced coach and a newcomer coach as described in this study. About this sharing of information, Galatti, Reverdito, Scaglia, Paes, Seoane ${ }^{37}$ and Talamoni, Oliveira, and Hunger ${ }^{38}$ emphasize that in working with a team of the coaching staff, they can share knowledge with the coach to avoid possible mistakes like overdoing the training load. While the coach is more focused on the technicaltactical components and the physical trainer is responsible for the physical part of the athletes, the nutritionist is responsible for power and energy replenishment, and the psychologist can help players stay focused on the training.

However, our findings show that discussions about sports training are much more centralized in each coaching staff group without having a greater sharing of information among the coaches of the different groups (U10-U17) (C1, C3, C5, TC2, and TC4). When surveying an English Football Club, Cushion and Jones ${ }^{39}$ considered the coaches and the training department conservative, not being open to changes. Mesquita and collaborators ${ }^{6}$ obtained similar results in the study with volleyball, basketball, gymnastics, swimming, and handball coaches, who labeled their respective training environments most of the time as "competition rather than collaboration". Such evidence confirms the concern of Gilbert and Trudel ${ }^{10,15}$, showing a traditional culture, with lack of communication and cooperation, still rooted in some sports' working environments.

To ensure co-operation rather than competition among professionals, it seems interesting that Clubs with performanceoriented sports activities create and manage strategies for the joint development of the coaching group. Thus, "free theme meetings" (C7 and TC4) can be framed as a positive initiative of the club to encourage the sharing of information among coaches and other professionals such as psychologists, coordinators, and others.

Thus, organizing these ongoing meetings may be a key strategy to encourage purposeful discussion between coaching staff groups and the observation of other coaches in situational coaching experiences ${ }^{6,10,13-15}$, by creating a bigger interaction with the coaching staff as a whole (-8,36. $^{6}$

In addition, this increased interaction among club professionals can better guide coaches on the development of a new athlete training program ${ }^{10,15}$. Conducting meetings or systematic and versatile conversations is recognized by Illeris ${ }^{16}$, Gilbert and Trudel $^{10,15}$, and Garvin, Edmondson, and Gino ${ }^{35}$ as favoring a learning and engagement in problem solving, similar to the one reported by the coaches and technical coordinators interviewed (C5, C7, C8, TC1, TC2, TC3, and TC4). For Gilbert and Trudel ${ }^{10}$, this action can bring coaches together in favor of the common goal aimed by the Club in training athletes. Facilitating such meetings more frequently may happen, according to Gilbert and Trudel $^{15}$, by organizing small discussion groups, in which more experienced coaches, would be responsible for coordinating the discussion.

\section{The incentive for continuing education}

In this theme, we explore the interest of the club managers in providing financial assistance to their professionals 
(coaches being one among them), so that they can take or deliver courses for improvement $(\mathrm{C} 1, \mathrm{C} 2, \mathrm{C} 3, \mathrm{C} 8, \mathrm{TC} 1, \mathrm{TC} 2$, $\mathrm{TC} 3$, and TC4). This practice takes place after the managers analyze coaches' requests for courses to be taken outside the sports training center, in which the Club is responsible for covering all or part of the expenses. Also, the same happens when professionals of the club are invited to deliver lectures or courses nationally.

\section{"[...] last year I had the opportunity to participate in a course which the Club helped me (financially) and it was of great value and maybe that was the course [...] that I thought it was the best. I got new ideas that I am already implementing [...]" (C3). "[...] the Club encourages me, many times they helped me to pay the course. We even have the Club's own professionals delivering courses at the Brazilian Football Confederation" (TC1).}

While the participants value the support given by the Club for their training and development as coaches through courses held outside the training center, in the findings of Szezerbicki, Pilatti, Kovaleski, de Francisco ${ }^{9}$, the Club intended to provide to its professionals with a way of professional training within its own sports training center, including an implementation project of the "football university" for coach development.

In addition to specialists sharing information inside the club, there were also opportunities to bring in specialists from outside the organization. The aim of these meetings with the specialists would be to regularly share information (reflective cards) and knowledge (training sessions) in a productive, fast, and precise way so the coach can reflect on the different points of view that can affect key decisions in the organization ${ }^{18}$. After taking courses after graduation, the coaches already have experience and can reflect deeply on their performance and the issues faced in their daily environments ${ }^{3}$. In another study, Belão, Machado, and $\mathrm{Mori}^{4}$, found that the coaches in their study showed more confidence after taking post-graduate courses and short-term courses specific to Rhythmic Gymnastics.

In addition to the possibility of providing training courses to the coaches, another possibility for the development of coaches, according to Milistetd, Peniza, Trudel, Paquette ${ }^{18}$, would be to include a 'Personal Learning Coach' in this process. A coaching facilitator can favor deep reflection and the coach's self-awareness about their practice, focusing on their coaching activities, and having greater ease of communication and connection with their athletes.

\section{Club Pillars}

The club has a philosophy regarding coaches' development that includes three pillars to guide coaches: The first is having transparency of the club's goals; the second pillar strengthens the continuity of the coaches in the club and the long-term work with the athletes; and the third relates to including an evaluative component to analyze if the coaches meet the goals set by the club.

\section{Club goals}

In addition to the support schemes presented previously, the learning organization is managed by the philosophy that systematizes the thoughts and actions of the coaches in the Club. As several participants noted, it requires transparency of the goals as in the organization of each team throughout the training process $(\mathrm{C} 2, \mathrm{C} 8, \mathrm{TC} 1, \mathrm{TC} 2$, and $\mathrm{TC} 3)$.

\section{"[...] it was the Club that set me for what I am today [...] it made me develop even more as a person and as a coach, made me look for much more, made me grow up in many aspects, in both technical and tactical, players choosing, team setting [...]" (C2). "[...] I believe that knowing how to manage a group, having a good relationship with all athletes in the group, with everybody in the coaching staff, a trust relationship, having the ambition of growing inside the Club, of one day getting to the high performance [...]. As a return to the Club, the crucial is the athlete's training, [...] so that the athletes can have a perspective in the Club to get to the professional level" (TC1).}

The clarity in the Club goals helps coaches to understand the needs and responsibilities to act in an Elite Club. It helps in the understanding that the athletes' training involves not only sport-specific issues but also a component of maintaining a good relationship with athletes.

\section{Continuity of coaches}

Conducting discussions among coaches and providing opportunities for coaches to go to out-of-club courses to build on their practice seems to depend on a "continuity of coaches" (C6, C8, TC1, TC2, TC3, and TC4) at the club with a long-term systematization of that process. Thus, coaches will be able to thoroughly evaluate their own work and learn from the reflection on their experiences. During the interviews, four coaches had been at the club for at least four years and two coaches had been at the club for at least 10 years.

“[...] I see (it) as a very stable Club, something that encourages you to stay inside the Club, with a coordination that has been in the Club for a long time, which gives you a way and a continuity for you to keep up with your work [...]" (C6).

"We have been following their (coaches) methodology from the beginning and they are working. We (managers) are already drawing a parallel of their methodology with our methodology. Then $90 \%$ of them come from the Club Youth 
'Football School', [...] we always prefer the coach who is already in the club to move from training the younger to a team with more experienced athletes $[\ldots] "(T C 3)$.

The continuity of the coaches in the club can start in the period of undergraduate internship and continue for several years. Despite possible changes in the Club's management every two years, coaches generally stay, allowing more confidence in the development of the program established by the Club.

\section{Evaluation of coaches}

Four coaches $(\mathrm{C} 1, \mathrm{C} 4, \mathrm{C} 5$, and $\mathrm{C} 8)$ and all the coordinators (TC1, TC2, TC3, and TC4) talked about the Club's guidance and evaluation demands. In the case of this study, coaches are evaluated for their behavior and how they prepare their players in the specific aspects of the sport and on social values (TC4).

The club advocates for coach evaluations as part of their development. The quality of the coaches' work depends not only on the actions encouraged by the learning organization, but also on the coaches themselves as they are open to receive and share information with their peers and with other club professionals such as coordinators to develop each coach respecting the philosophy of the club. As such, the coaches are observed and have discussions about their coaching on a regular basis for better coaching practices and an approximate line of reasoning between coaches.

"[...] about the methodological (training) part, the
Club is discussing, looking for a methodological
standard for the coaches and making them have
not equal thoughts, but similar in order to develop
and enhance the athletes' training" (C1).
"[...] we demand a lot from the coaches concerning
the training, but also a behavior issue. We always
say: "in here, we have to form the athlete and
the citizen" [...] today there is a, we can say, an
evaluation department that works (observation and
discussion with the coaches) on these issues" (TC4).

The surveyed coaches explained their duties and the interest in taking athletes to a higher level in their training, with a bigger and more qualified number of players. In this sense, the evaluations seem to be specifically related to coaches' understanding of the philosophy of the Club regarding training of young athletes, making the training based on social values for the development of citizens (C1, C4, C5, C8, TC1, TC2, TC3, and TC4).

"Club pillars" seem to help define coaches' approach to their athletes' long-term sports development, as well as the transparency of club goals and evaluation reported by coaches and technical coordinators (C2, C8, TC1, TC2 and TC3).

As guided by the philosophy of the club, C2 and TC1 described that in the development process of their athletes, in addition to learning content, their training involves maintaining good relationships between the coaching staff and the athletes, and among the athletes themselves. Nunomura, Oliveira, Roble, Carbinatto ${ }^{40}$ and Cassidy, Jones, and Potrac ${ }^{5}$ warn that sports organizations vary in their philosophical notions, values, planning, the success of the instrumentation, and capacity in modifying and transforming. Thus, in spite of the importance reported by coaches and coordinators of this study on following club goals (C2, C8, TC1, TC2, and TC3), in the study of Jones, Armour, and Potrac ${ }^{34}$, the coach points out that, even when following a program set by the Club, he had created in the building of new exercises, as he would not be successful if he adopted another direction concerning the goals.

To facilitate the understanding of the club's goal with young athletes, coaches need continuity and experience in their sporting context. The safety of his career at the club motivated C2 to continue working at the club and to show the paths he still needs to take. For Mallett, Rynne, Dickens ${ }^{7}$, Garvin, Edmondson, and Gino $^{35}$ and Illeris ${ }^{16}$ professionals need time to be evaluated, which was reported by $\mathrm{C} 6$, who stated that he could verify the continuity of his work.

Another question concerns the progression of the coaches within the club, where they start as coaches of the youngest athletes $(\mathrm{U} 10, \mathrm{U} 11, \ldots)$ and after an undefined experience, they move up to train more experienced athletes (U15, U16, ...). However, each age level and sport context (participation sports, emerging athletes, athletes' development, and high performance) has its own specificities and should not have a goal to form professionals for the succeeding categories or other contexts, but to prioritize expert coaches for each age, formative period, and athletes' context. An example involves the notion of early maturity and delayed maturity and its consequences for sports training, which differs from the training needs of highperformance athletes ${ }^{41,42}$. The participants from the club in this study usually follow the same group of athletes that they trained the previous year (they might move up from U12 to U13). This can reduce the impact of group changes on coaches.

Jones, Armour, and Potrac ${ }^{34}$, noted that the nature of coaches' intense work added to already great expectations by the Club, demands from the coach the commitment and desire to achieve success. However, for this to occur, Gilbert and Trude ${ }^{15}$ and Nunomura, Oliveira, Roble, Carbinatto ${ }^{40}$ highlighted that the coaches need to feel confident in order to experiment and reflect, that their evaluation would not simply be by wins or losses. Nunomura, Oliveira, Roble, Carbinatto ${ }^{40}$ also point out their concern about "winning by any means", in which some coaches and athletes aim only for competitive results, means that the coach strays increasingly farther from a humanistic and educational approach, with low valuing of fair play and social values such as respect.

It is also important to highlight that, as Garvin, Edmondson, and Gino ${ }^{35}$ show, there is a challenge in judging the evaluation process in a critical-reflexive way and to apply this support for a real learning organization. Gilbert and Trudel $^{10,15}$ pointed out some of the implications for the management of sports organizations. In order to create an environment that nurtures the reflective coaches' practice, it is necessary to encourage certain freedom for coaches in the training design so that they can work their creativity. Otherwise, coaches can be dependent 
on old strategies that may not develop young athletes holistically in order to reach the professional level. By following these guidelines, the schemes and pillars presented by coaches and technical coordinators can create knowledge and sustain a learning organization. However, for some authors $2,11,12,16$ the success of such organizations depends on the mind change of each individual; such is the case in this study with the directors and coordinators who evaluate the coaching staff and the coaches who teach the athletes.

\section{Conclusion}

From the findings, we noted that the Sports Club studied is structuring and organizing support schemes and pillars of action for the coaches' development. The schemes (mentoring and meeting, incentive for continuing education, and club pillars) and their combined and continuous actions, as the "free theme meetings", can facilitate coaches' better engagement with their peers, athletes, coaching staff, directors, and professionals from other areas (physiotherapists, psychologists, social workers, nutritionists, among others). This interaction has the potential of creating coach learning. The greater interaction of coaches and technical coordinators was identified through data triangulation, demonstrating that each strategy described is intentionally organized by the club and identified by the coaches as an opportunity to learn.

We highlight the possibility of sports clubs to become a learning organization, promoting communication amongst professionals and their ongoing update through courses and meetings; providing a safe work environment; and engaging coaches in the Club's organizational culture to help their education and development. Thus, other clubs should consider these aspects of replication. Despite the likely greater demand for time and hard work, this guidance has the potential to assist in the effective training of athletes and also to achieve the desired results, not only in the competitive context but also in the holistic development of the elite football athletes as people in society.

Despite the contributions of this study, the lack of secondary sources (documents that reinforce quotes, such as transparency of club goals, coaches' contracts with the club, coaches' assessments, among others) can be mentioned as a limitation, especially to expand the data analysis conducted within the interviews. Thus, to assure a more detailed data analysis and to explore more robust, clear, and significant data ${ }^{43}$, we chose to analyze first the perceptions reported by more than one coach, later by two or more technical coordinators. Another limitation is the inclusion of a single case, which hinders data generalization. However, it is important to highlight that the investigated case is considered in Brazil as one of the best in the training of young football athletes ${ }^{24}$. Thus, by understanding the case better, other clubs can adopt and adapt the strategies described for the development of their coaches.

It is recommended that scholars continue to conduct investigations in this topic (such as action research) to follow the actions reported in this study (e.g. systematic meetings), in order to check in detail the sports clubs as places of meaningful learning for sports coaches.

\section{References}

1. Côté J, Gilbert W. An integrative definition of coaching effectiveness and expertise. Int J Sports Sci Coach. 2009;4(3):307-23. Doi: 10.1260/174795409789623892

2. Lara-Bercial S, Mallett C. The Practices and Developmental Pathways of Professional and Olympic Serial Winning Coaches. Int Sport Coach J. 2016;3(3):221-39. Doi: 10.1123/iscj.2016-0083

3. Tozetto AB, Galatti LR, Scaglia AJ, Duarte T, Milistetd M. Football coaches' development in Brazil: a focus on the content of learning. Motriz: J. Phys. Ed. 2017;23(3):1-9. Doi: 10.1590/ s1980-6574201700030017

4. Belão M, Machado LP, Mori PMM. A formação profissional das técnicas de ginástica rítmica. Motriz: J. Phys. Ed. 2009;15(1):61-8.

5. Cassidy TG, Jones RL, Potrac P. Understanding sports coaching: The social, cultural and pedagogical foundations of coaching practice. New York: Routledge; 2009.

6. Mesquita I, Ribeiro J, Santos S, Morgan K. Coach learning and coach education: Portuguese expert coaches' perspective. Sport Psychol. 2014;28(2):124-36. Doi: 10.1123/tsp.2011-0117

7. Mallett C, Rynne S, Dickens S. Developing high performance coaching craft through work and study. In: Denison P, editor. Routledge handbook of sports coaching. London: Routledge; 2013.

8. Rynne S, Mallett C, Tinning R. Workplace learning of high performance sports coaches. Sport Educ Soc. 2010;15(3):315-30. Doi: 10.1080/13573322.2010.493312

9. Szezerbicki AS, Pilatti LA, Kovaleski JL, de Francisco AC. Gestão do conhecimento em equipes de alta performance: o caso do Clube Atlético Paranaense. Produção Online. 2006;6(2):1-26. Doi: 10.14488/1676-1901.v6i2.287

10. Gilbert W, Trudel P. Learning to coach through experience: reflection in model youth sport coaches. J Teach Phys Educ. 2001;21:16-34. Doi: $10.1123 /$ jtpe.21.1.16

11. Jarvis P. Globalization, lifelong learning and the learning society: Sociological perspectives, lifelong learning and the learning society. Abingdon: Routledge; 2007.

12. Hunter-Johnson Y, Closson R. Adult educators' perceptions of their organization promoting learning practices and culture: A Caribbean law enforcement context. Adult Learn. 2012;23(4):178-87.

13. Nash C, Sproule J. Career development of expert coaches. Int J Sports Sci Coach. 2009;4(1):121-38. Doi: 10.1260/1747-9541.4.1.121

14. Erickson K, Côté J, Fraser-Thomas J. Sport experiences, milestones, and educational activities associated with high-performance coaches' development. Sport Psychol. 2007;21(3):302-16. Doi: 10.1123/tsp.21.3.302

15. Gilbert W, Trudel P. Learning to coach through experience: conditions that influence reflection. Phys Educ. 2005;62(1):32-43.

16. Illeris $\mathrm{K}$. The fundamentals of workplace learning: Understanding how people learn in working life. New York: Routledge; 2011.

17. Cushion C, Ford P, Williams A. Coach behaviours and practice structures in youth soccer: Implications for talent development. Journal Sports Sci. 2012;30(15):1631-41. Doi: 10.1080/02640414.2012.721930 
18. Milistetd M, Peniza L, Trudel P, Paquette K. Nurturing high-performance sport coaches' learning and development using a narrative-collaborative coaching approach. LASE J Sport Sci. 2018;9(1):6-38. Doi: 10.2478/ljss-2018-0001

19. Wright T, Trudel P, Culver D. Learning how to coach: the different learning situations reported by youth ice hockey coaches. Phys Educ Sport Peda. 2007;12(2):127-44. Doi: 10.1080/17408980701282019

20. Lemyre F, Trudel P, Durand-Bush N. How youth-sport coaches learn to coach. Sport Psychol. 2007;21(2):191-209. Doi: 10.1123/ tsp.21.2.191

21. Culver D, Trudel P. Clarifying the concept of communities of practice in sport. Int J Sports Sci Coach. 2008;3(1):1-10. Doi: $10.1260 / 174795408784089441$

22. Stake RE. The art of case study research. Thousand Oaks: Sage; 1995.

23. Baxter P, Jack S. Qualitative case study methodology: Study design and implementation for novice researchers. Qual Rep. 2008;13(4):544-59.

24. Paoli PB, da Costa FR, Ferreira Neto A, Goncalves Soares AJ. Identitary Representations in the Talent Selection Process. Movimento. 2010;16(4):135-50.

25. Brazil. Resolution CNE/CES 1/2007. Establishes standards for the operation of Lato Sensu Postgraduate courses at the specialization level. 2007.

26. Purdy L. Interviews. In: Nelson L, Groom R, Potrac P, editors. Research methods in sports coaching. 1. Abingdon, NY: Routledge; 2014.

27. Sparkes AC, Smith B. Qualitative research methods in sport, exercise and health: From process to product. Abingdon: Routledge; 2014.

28. Thomas DR. A general inductive approach for analyzing qualitative evaluation data. Am J Eval. 2006;27(2):237-46. Doi: $10.1177 / 1098214005283748$

29. Bardin L. Content Analysis. São Paulo: Edições 70; 2011.

30. Miles MB, Huberman AM. Qualitative data analysis: An expanded sourcebook. Thousand Oaks: Sage; 1994.

31. Shenton AK. Strategies for ensuring trustworthiness in qualitative research projects. Education for information. 2004;22(2):63-75. Doi: 10.3233/EFI-2004-22201

32. Patton MQ. Qualitative evaluation and research methods. Newbury Park: Sage; 1990.

33. Maxwell J. Understanding and validity in qualitative research. Harv Educ Rev. 1992;62(3):279-301. Doi: 10.17763/ haer.62.3.8323320856251826

34. Jones RL, Armour KM, Potrac P. Constructing expert knowledge: A case study of a top-level professional soccer coach. Sport Educ Soc. 2003;8(2):213-29. Doi: 10.1080/13573320309254

35. Garvin DA, Edmondson AC, Gino F. Is yours a learning organization? Harv Bus Rev. 2008;86(3):109. Doi: 10.13072/midss.116

36. Fenoglio R, Taylor W. From winning-at-all-costs to Give Us Back Our Game: perspective transformation in youth sport coaches. Phys Educ Sport Pedagogy. 2014;19(2):191-204. Doi: 10.1080/17408989.2012.748737
37. Galatti LR, Reverdito RS, Scaglia AJ, Paes RR, Seoane AM. Pedagogia do esporte: tensão na ciência e o ensino dos jogos esportivos coletivos. J Phys Educ. 2014;25(1):153-62.

38. Talamoni GA, Oliveira FIdS, Hunger D. As configurações do futebol brasileiro: análise da trajetória de um treinador. Movimento. 2013;19(1):73. Doi: 10.22456/1982-8918.29764

39. Cushion C, Jones RL. Power, discourse, and symbolic violence in professional youth soccer: The case of Albion Football Club. Sociol Sport J. 2006;23(2):142-61. Doi: 10.1123/ssj.23.2.142

40. Nunomura M, Oliveira MS, Roble OJ, Carbinatto M. Ginástica artística competitiva e a filosofia dos técnicos. Motriz: J. Phys. Ed. 2012. Doi: $10.1590 / \mathrm{S} 1980-65742012000400006$

41. Mallett C, Rynne S. Changing role of coaches across development. In: Baker JF, Damian, editor. Routledge Handbook of Sport Expertise. Abingdon: Routledge; 2015.

42. Mallett CJ, Trudel P, Lyle J, Rynne SB. Formal vs. informal coach education. Int J Sports Sci Coach. 2009;4(3):325-64. Doi: 10.1260/174795409789623883

43. Callary B, Werthner P, Trudel P. How meaningful episodic experiences influence the process of becoming an experienced coach. Qual Research Sport Exercise Health. 2012;4(3):420-38. Doi: 10.1080/2159676X.2012.712985

\section{Acknowledgements}

Fundação de Apoio à Pesquisa Científica e Tecnológica do Estado de Santa Catarina - FAPESC.

Fundação de Amparo à Pesquisa do Estado de São Paulo - FAPESP. Grant number 2015/01599-9, São Paulo Research Foundation.

The authors thank Espaço da Escrita - Coordenadoria Geral da Universidade - UNICAMP - for the language services provided.

\section{Corresponding author}

Alexandre Vinicius Bobato Tozetto

Center for Research on Sports Pedagogy, Federal University of Santa Catarina, Brasil.

Campus Reitor João David Ferreira Lima, s/n, Trindade, Florianópolis, SC Centro de Desportos, Bloco IV, Laboratório de Pedagogia do Esporte. Email: alexandrebobato@hotmail.com

Manuscript received on May 18, 2018

Manuscript accepted on February 20, 2019

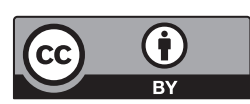

Motriz. The Journal of Physical Education. UNESP. Rio Claro, SP, Brazil - eISSN: 1980-6574 - under a license Creative Commons - Version 4.0 